\title{
THE STUDY OF HEAVY METAL CONCENTRATIONS IN THE RED MUD DEPOSITS AT THE GULF OF CORINTH, USING MULTIVARIATE TECHNIQUES
}

\author{
Iatrou M., Papatheodorou G., Geraga M. and Ferentinos G. \\ University of Patras, Department of Geology, Laboratory of Marine Geology and Physical Oceanography, \\ 26500 Patras, Greece, iatroum@upatras.gr,gpapatheodorou@upatras.gr
}

\begin{abstract}
Detailed geochemical analyses were performed on the recent sedimentary cover $(0-15 \mathrm{~cm})$ of the northern flank of the Gulf of Corinth, in western Greece. Man-made metalliferous deposits have been formed on the sea-bed of the Gulf due to the discharge of red mud tailings on the shelf of the Antikyra Bay. The metalliferous deposits have been incorporated in the sedimentation regime of the area. A large grid of sediment samples collected from surface and subsurface red mud deposits and the surrounding natural sediments were analysed for $\mathrm{Ag}, \mathrm{Al}, \mathrm{Cd}, \mathrm{Co}, \mathrm{Cr}, \mathrm{Cu}, \mathrm{Fe}, \mathrm{Hg}, \mathrm{Mg}, \mathrm{Mn}, \mathrm{Ni}, \mathrm{Pb}, \mathrm{Si}, \mathrm{Ti}, \mathrm{V}$, and $\mathrm{Zn}$ concentrations, using Atomic Absorption Spectrometry (AAS). Also, Total Organic Carbon and Calcium Carbonates were determined. Additionally, correlation between heavy metal concentrations and grain-size data was examined. High heavy metal content values were measured on the floor of the Corinth basin, but the highest heavy metal concentrations occur near the discharge site. In subsurface sediments the heavy metal content ( $\mathrm{Fe}, \mathrm{Ni}, \mathrm{Cr}, \mathrm{Pb}, \mathrm{V}, \mathrm{Ag}, \mathrm{Co}, \mathrm{Al}, \mathrm{Cd}, \mathrm{Ti}, \mathrm{Hg}$ ) is significantly higher in the red and reddish mud sediments than in the natural mud sediments. The heavy metal content values decrease from top to base within red-mud deposits. Multivariate statistical methods (Cluster and Facto analysis) were applied on the heavy metal composition and grain-size dataset in order to investigate the inter-element relationships as well as the relationships between the geochemical and sedimentological data.
\end{abstract}

Key words: red mud tailings, geochemical concentrations, $R$-mode factor analysis, cluster analysis, Corinth Gulf.

\section{Introduction}

The geochemical composition of recent marine deposits in urban and industrialized areas is a result of the contribution of natural environmental factors and a wide range of human activities (Borrego et al, 2002). The marine disposal of industrial wastes such as the bauxitic (red-mud) tailings constitutes an important human input of heavy metals to marine environment (Grey and Baseden, 1976) on a regional scale.

This study deals for the first time with a group of samples which cover the overall study area and constitutes a preliminary presentation of the results. It presents the geochemical signature of surface and subsurface samples in order to establish the distribution of the studied compounds spatially and also temporally via the subsurface sedimentary layers.

This study also aims to explore the inter-relationships of major and minor elements in red-mud slurry and in natural sediments by using multivariate statistical methods, such as factor and cluster analysis. These methods have been applied widely on geochemical data to study their spatial distribution and the 
interrelations between metal concentrations (Papatheodorou et al., 1999; Papatheodorou et al., 2002; Sanchez-Garcia et al., 2009) and on geochemical and granulometric components (Borrego et al., 2002).

\section{Material and Methods}

\subsection{Study Area}

The Gulf of Corinth is an elongated embayment in western Greece (Fig. 1a). The morphology of the northern margin of the Gulf consists of a wide shelf, in Antikyra Bay, which passes through a steeping slope and ends to a deep basin floor at $890 \mathrm{~m}$ water depth (Brooks and Ferentinos, 1984). In Antikyra Bay there is a significant anthropogenic input in the sedimentation regime of the area. Massive bauxite residue tailings are being discharged on the shelf floor for more than 40 years from an Aluminum processing plant. As it is presented by Iatrou et al. (2007) these materials have formed significant metalliferous deposits on the shelf and the basin floor and have been admixed with the natural sediments.

\subsection{Datasets and geochemical analysis}

A large grid of more than 100 short cores have been collected from the seafloor of the study area in order to study the recent sedimentation layer $(0-15 \mathrm{~cm})$ which has been affected by the deposition of the red-mud tailings. Surface subsamples were collected from each short core as well as subsurface samples from the majority of the short cores composing a large dataset. Sediment samples were initially analyzed for their grain-size components using sieve-pipette method. Next, major and minor elements concentrations (Ag, Al, Cd, Co, Cr, Cu, Fe, Hg, Mg, Mn, Ni, Pb, Si, Ti, V, and Zn) were determined on a Carbonate Free Basis using total decomposition method through a Perking Elmer 3100 atomic absorption spectrograph. Also Organic Carbon and Calcium Carbonate concentrations were determined.

\subsection{Data Treatment}

Consideration of the many possible inter-related physical and chemical controls that might be operative in dataset led to the decision that the chemical and physical data should be analyzed separately. Thus in the present study the multivariate analysis was performed on three separate subsets of the original data using the commercial statistics software package SPSS v 14.0. Subset 1 consists of the geochemical concentrations of each surface and subsurface sediment sample, while the subset 2 comprises of the geochemical compositions for the surface samples. The subset 3 incorporates the geochemical compositions and the grain-size components of the surface sediment samples.

Most of statistical methods of data analysis require that the observations conform to normal distribution. Thus, a Kolmogorov-Smirnov test of normality was applied on the three subsets, which showed that not all the variables were normally distributed with $95 \%$ confidence interval. Therefore statistical treatment was carried out on subset 1 where the raw data were standardized according to the method used by Reimann and Filzmoser (2000). However subsets 2 and 3 were not subjected on any treatment in order to explore the raw data.

To identify the relationship among minor and major elements that exist in red-mud tailings and in natural sediments as well as their possible sources, subset 1 and subset 2 were analyzed using Factor Analysis. Factor analysis is a multivariate technique of data reduction that examines the interdependence of variables providing knowledge of the underlying structure of data (Davis, 2002). Subset 3 was analyzed applying hierarchical cluster analysis. This was due to the fact that grain-size components were co-dependent variables; therefore factor analysis could not be performed (Davis, 2002). Clusters were produced using between groups linkage method with Pearson correlation as similarity measurement. 


\section{Results}

\subsection{Bulk geochemistry and granulometry}

Table 1 shows the concentration range and mean in carbonate free basis, of heavy metals, calcium carbonate and organic carbon in the red mud and natural sediments from the Antikyra Bay and the Corinth Gulf. The red-mud tailings are highly enriched in $\mathrm{Fe}, \mathrm{Ti}, \mathrm{Cr}, \mathrm{Ni}, \mathrm{Co}, \mathrm{Pb}$, and $\mathrm{Cu}$, compared to the surrounding natural sediments. On the contrary, natural sediments are characterized by high concentrations of $\mathrm{Mn}, \mathrm{Zn}$, and $\mathrm{CaCO}_{3}$, compared to the red-mud deposits.

Table 1. Bulk geochemical concentrations of red mud and natural sediments in Antikyra Bay and Corinth Gulf.

\begin{tabular}{|l|c|c|c|c|c|c|c|c|c|}
\hline \multirow{2}{*}{} & \multicolumn{2}{|c|}{ Red mud in Antikyra Bay } & \multicolumn{2}{|c|}{ Red mud in Corinth Gulf } & \multicolumn{3}{|c|}{ Natural sediments } \\
\cline { 2 - 12 } & Min & Max & Mean & Min & Max & Mean & Min & Max & Mean \\
\hline $\mathrm{Fe}^{\mathrm{a}}$ & 30,4 & 40,4 & 35,8 & 33,7 & 36,7 & 35 & 4,92 & 16,92 & 8,42 \\
\hline $\mathrm{Ti}^{\mathrm{a}}$ & 5,1 & 5,8 & 5,4 & 2,31 & 2,32 & 2,31 & 0,11 & 1,69 & 0,53 \\
\hline $\mathrm{Al}^{\mathrm{a}}$ & 11,9 & 13,8 & 13,1 & 11,5 & 12,4 & 12,1 & 0,1 & 10,82 & 7,29 \\
\hline $\mathrm{Si}^{\mathrm{a}}$ & 5,4 & 5,8 & 5,6 & 6,2 & 6,8 & 6,5 & 6,37 & 38,12 & 21,46 \\
\hline $\mathrm{Mg}^{\mathrm{a}}$ & 3,05 & 8,96 & 5,30 & 4,30 & 10,15 & 6,47 & 4,04 & 12,14 & 6,29 \\
\hline $\mathrm{Pb}^{\mathrm{b}}$ & 195 & 159 & 162 & 111 & 145 & 131 & - & 101 & 30 \\
\hline $\mathrm{Cu}^{\mathrm{b}}$ & 110 & 148 & 133 & 125 & 137 & 133 & 29 & 101 & 57 \\
\hline $\mathrm{Hg}^{\mathrm{b}}$ & 4,8 & 5,9 & 5,0 & 2,6 & 3,2 & 2,8 & - & 2,1 & 0,34 \\
\hline $\mathrm{Co}^{\mathrm{b}}$ & 81 & 127 & 103 & 83 & 100 & 92 & - & 58 & 32 \\
\hline $\mathrm{Cr}^{\mathrm{b}}$ & 2950 & 4312 & 3441 & 1030 & 1210 & 1120 & - & 753 & 207 \\
\hline $\mathrm{Ni}^{\mathrm{b}}$ & 1498 & 1728 & 1624 & 1126 & 1169 & 1147 & 65 & 854 & 231 \\
\hline $\mathrm{Ag}^{\mathrm{b}}$ & 7,6 & 12,1 & 9,6 & 6,0 & 8,2 & 7,3 & - & 7,0 & 0,83 \\
\hline $\mathrm{V}^{\mathrm{b}}$ & 601 & 718 & 673 & 548 & 600 & 571 & 58 & 222 & 142 \\
\hline $\mathrm{Cd}^{\mathrm{b}}$ & 6,0 & 11,6 & 10 & 6,5 & 11 & 7,9 & - & 9,5 & 0,7 \\
\hline $\mathrm{Zn}^{\mathrm{b}}$ & 95 & 112 & 108 & 124 & 143 & 135 & 89 & 326 & 218 \\
\hline $\mathrm{Mn}^{\mathrm{b}}$ & 800 & 1483 & 1325 & 2338 & 3501 & 2914 & 1292 & 8674 & 4044 \\
\hline $\mathrm{CaCO}_{3}{ }^{\mathrm{b}}$ & 30,25 & 85,87 & 48,88 & 24,04 & 65,55 & 44,01 & 35,13 & 51,19 & 46,21 \\
\hline $\mathrm{Corg}^{\mathrm{a}}$ & 0,20 & 2,90 & 0,58 & 0,30 & 1,10 & 0,73 & 0,10 & 3,20 & 1,02 \\
\hline & & & & & & & & & \\
\hline
\end{tabular}

a $(\%)$

${ }^{\mathrm{b}}\left(\mathrm{ppm}=\mathrm{mgkg}^{-1}\right)$

Red mud tailings on the shelf and the basin floor are mainly composed of silt and clay fractions (Table 2), whereas natural sediments on the shelf and the basin contain coarser components. 
Table 2. Bulk granulometric composition of red mud and natural sediments in Anikyra Bay and Corinth Gulf.

\begin{tabular}{|l|c|c|c|c|c|c|c|c|c|}
\hline \multirow{2}{*}{} & \multicolumn{3}{|c|}{ Red mud in Antikyra Bay } & \multicolumn{3}{c|}{ Red mud in Corinth Gulf } & \multicolumn{3}{c|}{ Natural sediments } \\
\cline { 2 - 10 } & Min & Max & Mean & Min & Max & Mean & Min & Max & Mean \\
\hline sand (\%) & 0,1 & 4,9 & 1,8 & 0,1 & 37,3 & 2,7 & 0,5 & 94,6 & 44,2 \\
\hline silt (\%) & 34,7 & 53,2 & 44,5 & 33,7 & 66,1 & 43,2 & 2,8 & 50,6 & 26,4 \\
\hline clay (\%) & 46,6 & 61,1 & 53,7 & 23,1 & 65,9 & 54,1 & 2,7 & 64,0 & 29,4 \\
\hline
\end{tabular}

\subsection{Subset 1}

An R-mode factor analysis, using a varimax solution, was applied to the full geochemical dataset (18x162) using the standardized data. Based on a combination of common criteria for factor selection used by Davis (1986), the most significant five factors were taken. The five factors account for more than $82 \%$ of the information among the variables. Communalities are high $(>0.70)$ for all variables. The five-factor model explains the variability for all variables and can be used to indicate the geochemical processes that modulate the composition of the recent sedimentary cover of the study area, without losing any significant characteristics.

Factor scores are plotted to describe relationships between samples. The temporal (with depth) distribution of factor scores was presented by plotting the score values of each short core along sampling traverses with an east-west direction. Each short core is depicted with the surface and subsurface sub-sample sites.

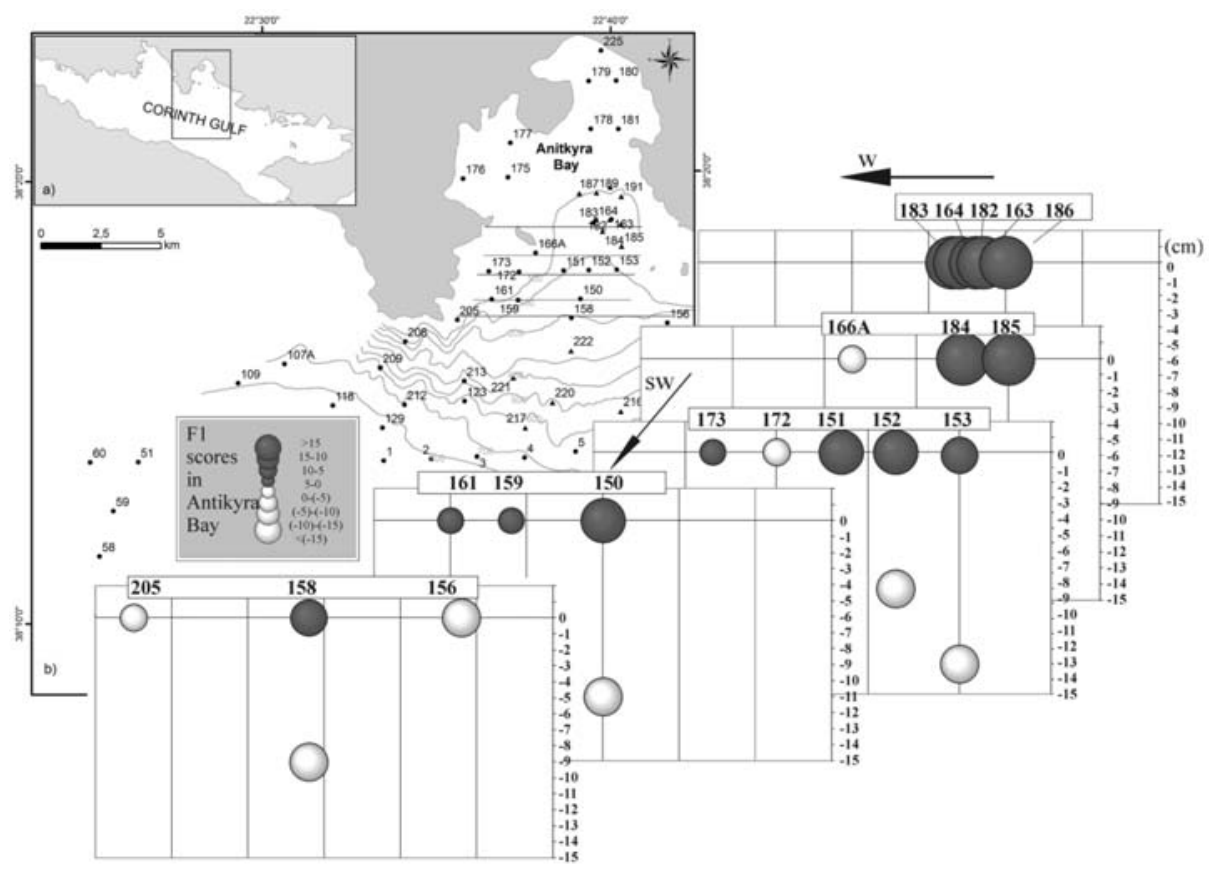

Fig. 1: (a) Study area; (b) Temporal distribution of factor 1 scores on selected sample sites in Antikyra Bay versus sediment depth (in $\mathrm{cm}$ ). 


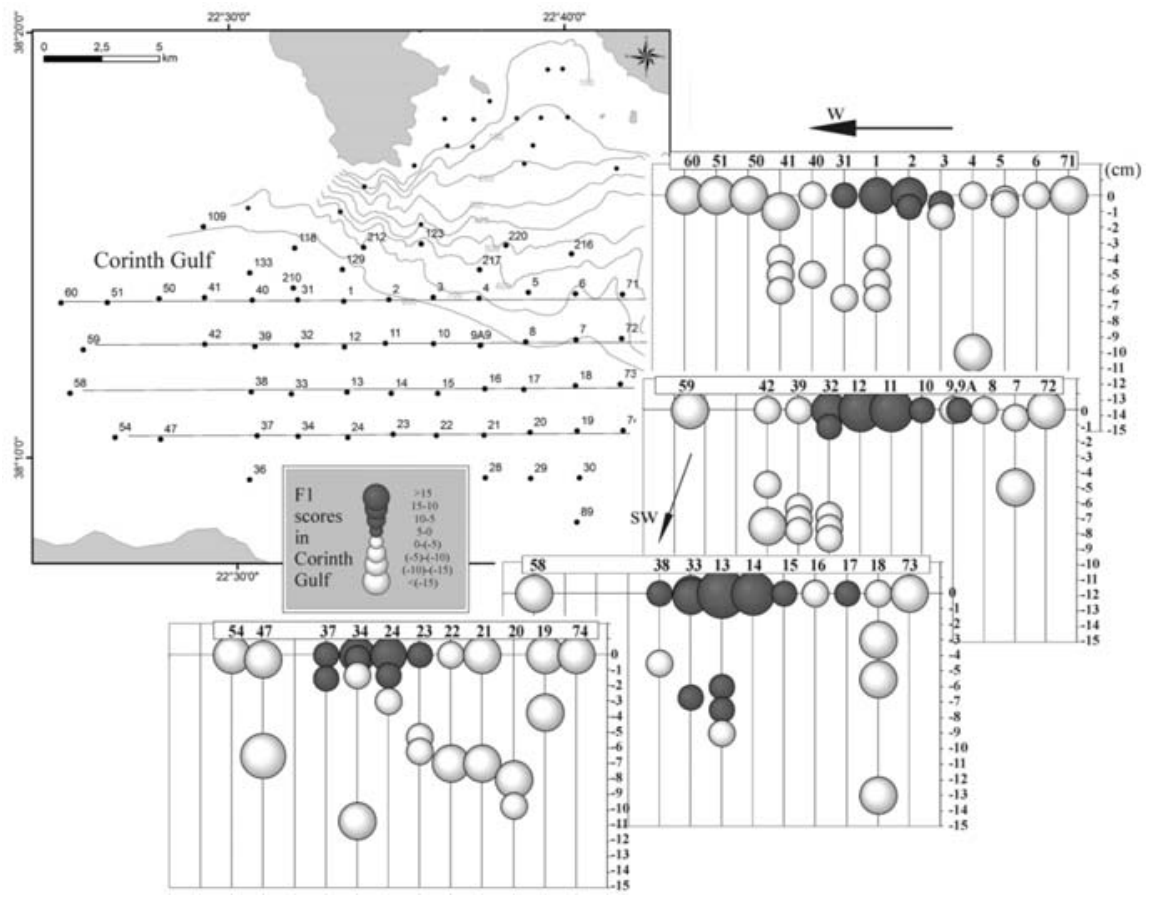

Fig. 2: Temporal distribution of factor 1 scores on selected sample sites in Corinth Gulf versus sediment depth (in $\mathrm{cm}$ ).

The first factor (F1) explains the largest proportion $(46.42 \%)$ of the total variance and has high positive loadings on $\mathrm{Fe}, \mathrm{Ti}, \mathrm{Al}, \mathrm{Pb}, \mathrm{Cu}, \mathrm{Hg}, \mathrm{Co}, \mathrm{Cr}, \mathrm{Ni}, \mathrm{Ag}, \mathrm{V}$ and $\mathrm{Cd}$. These metals are associated with red mud tailings. The temporal distribution of F1 scores on the surface and subsurface sample sites shows that the high positive values of this factor coincide with the red-mud tailings deposits. Higher values are observed among the surface red mud samples. The highest values however are in the surface red-mud samples from Antikyra Bay (Fig. 1b). Factor scores obtain lower positive values in the subsurface samples, that is F1 decreases with depth (Fig. 2). F1 is considered to be a red-mud factor which presents the variation of the red-mud tailings geochemical composition from past (subsurface layers) to present (surface layer).

The second factor (F2) explains a significant portion (10.9\%) of the total variance. F2 is a negative factor with high loading values on $\mathrm{Si}$ and $\mathrm{Mg}$. According to the temporal distribution of factor scores F2 has higher negative values in the surface and subsurface samples which are not associated to red-mud tailings but are natural sediments.

However, no significant variation was observed in the score values between the surface and subsurface natural sediment samples. The samples with the high score values also show high levels of concentration on $\mathrm{Si}$ and $\mathrm{Mg}$. Therefore, F2 may explains the association of $\mathrm{Mg}$ with the silicate fraction of the sediments.

The third factor (F3) explains a significant part (10.7\%) of the total variance and shows high negative loadings on $\mathrm{Mn}$ and $\mathrm{Zn}$. Factor 3 has higher negative factor scores on non red-mud sediments. Score values are higher on the surface samples of the short cores from the basin floor and 


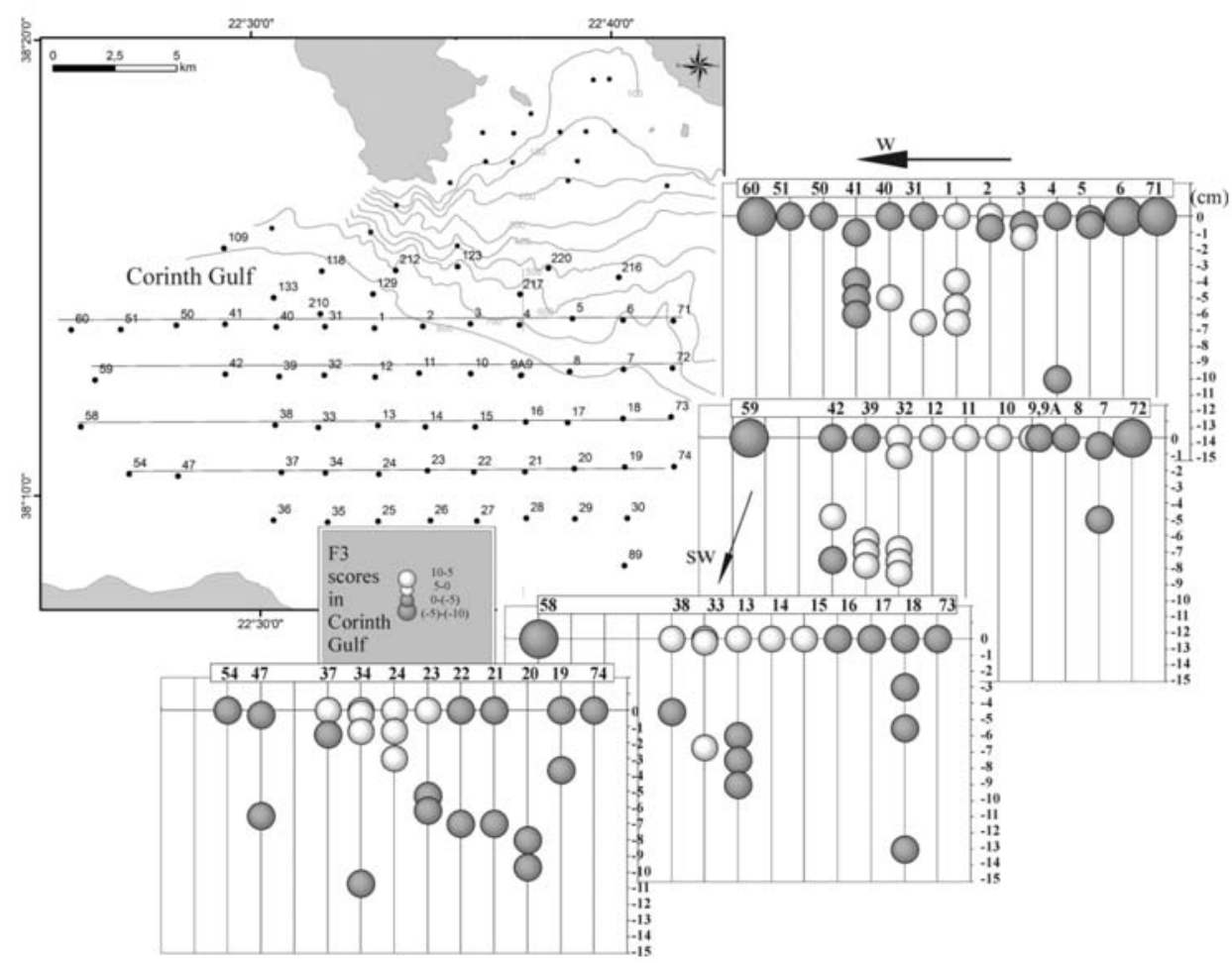

Fig. 3: Temporal distribution of factor 3 scores on selected sample sites in Corinth Gulf versus sediment depth (in $\mathrm{cm}$ ).

especially those on the east and west extremities of the basin (Fig. 3). These samples also show high levels of Mn and Zn. F3 may accounts for the Mn-hydroxide phase of the sediments which has absorbed $\mathrm{Zn}$.

The fourth factor (F4) explains $7.3 \%$ of the total variance. $\mathrm{F} 4$ has high positive loadings in $\mathrm{CaCO}_{3}$ According to temporal distribution of this factor, high factor scores show primarily natural sediment samples and few surface red mud samples. These samples have higher percentage of sand component and therefore this factor could explain the carbonate-sandy fraction of sediments.

The fifth factor (F5) explains $7.2 \%$ of the total variance and has high negative loading values in Corg. Temporal distribution of factor scores shows that it has higher values in natural surface /subsurface sediments and in few red-mud samples located in the periphery of the basin floor. On the contrary the lowest values are observed among the red-mud samples on the shelf and in the central basin. F5 accounts for the organic fraction and cannot be associated with another mineral.

\subsection{Subset 2}

Subset 2 consists of the geochemical raw dataset which involves the metal concentrations of the surface sediment samples (18x101). R-mode varimax factor analysis was carried out on the subset 2 and the four most significant factors were selected. They account for the $82.52 \%$ of the total variance. Communalities are high $(<0.69)$ for all variables (Table 3). 
Table 3. R-mode varimax factor matrix of geochemical data for subset 2.

\begin{tabular}{|l|c|c|c|c|c|}
\hline Variable & $\mathrm{F} 1$ & $\mathrm{~F} 2$ & $\mathrm{~F} 3$ & $\mathrm{~F} 4$ & Communalities \\
\hline $\mathrm{Fe}$ & 0.87 & & & & 0.88 \\
\hline $\mathrm{Ti}$ & 0.70 & 0.48 & & & 0.78 \\
\hline $\mathrm{Al}$ & 0.81 & & & & 0.70 \\
\hline $\mathrm{Si}$ & -0.67 & & 0.57 & & 0.77 \\
\hline $\mathrm{Mg}$ & -0.75 & & & & 0.77 \\
\hline $\mathrm{Pb}$ & 0.78 & 0.51 & & & 0.88 \\
\hline $\mathrm{Cu}$ & 0.86 & & & & 0.80 \\
\hline $\mathrm{Hg}$ & 0.83 & & & & 0.86 \\
\hline $\mathrm{Co}$ & 0.82 & & & & 0.76 \\
\hline $\mathrm{Cr}$ & 0.76 & 0.50 & & & 0.87 \\
\hline $\mathrm{Ni}$ & 0.80 & & & & 0.90 \\
\hline $\mathrm{Ag}$ & 0.79 & & & & 0.91 \\
\hline $\mathrm{V}$ & 0.76 & 0.47 & & & 0.89 \\
\hline $\mathrm{Cd}$ & 0.75 & 0.45 & & & 0.79 \\
\hline $\mathrm{Zn}$ & & -0.79 & & & 0.73 \\
\hline $\mathrm{Mn}$ & & -0.85 & & & 0.74 \\
\hline $\mathrm{CaCO}{ }_{3}$ & & & 0.93 & & 0.89 \\
\hline $\mathrm{Corg}$ & & & & -0.89 & 0.95 \\
\hline $\mathrm{Variance} \mathrm{explained} \mathrm{( \% )}$ & 49.1 & 17.6 & 9.0 & 6.8 & \\
\hline $\mathrm{Cumulative} \mathrm{variance}(\%)$ & 49.1 & 66.7 & 75.7 & 82.5 & \\
\hline & & & & & \\
\hline
\end{tabular}

Factor 1 explains the largest proportion (49\%) of the total variance and has high positive loadings on $\mathrm{Fe}, \mathrm{Ti}, \mathrm{Al}, \mathrm{Pb}, \mathrm{Cu}, \mathrm{Hg}, \mathrm{Co}, \mathrm{Cr}, \mathrm{Ni}, \mathrm{Ag}, \mathrm{V}$ and $\mathrm{Cd}$. These positive values are opposed by moderate negative loading values on $\mathrm{Si}$ and $\mathrm{Mg}$. The surface distribution of Factor 1 scores (Fig. 4) depicts the bipolar nature of this factor. Factor 1 primarily expresses the spatial distribution of the red-mud components and secondary the spatial distribution of natural sediments on the Antikyra shelf, especially those that are of silicate composition. 


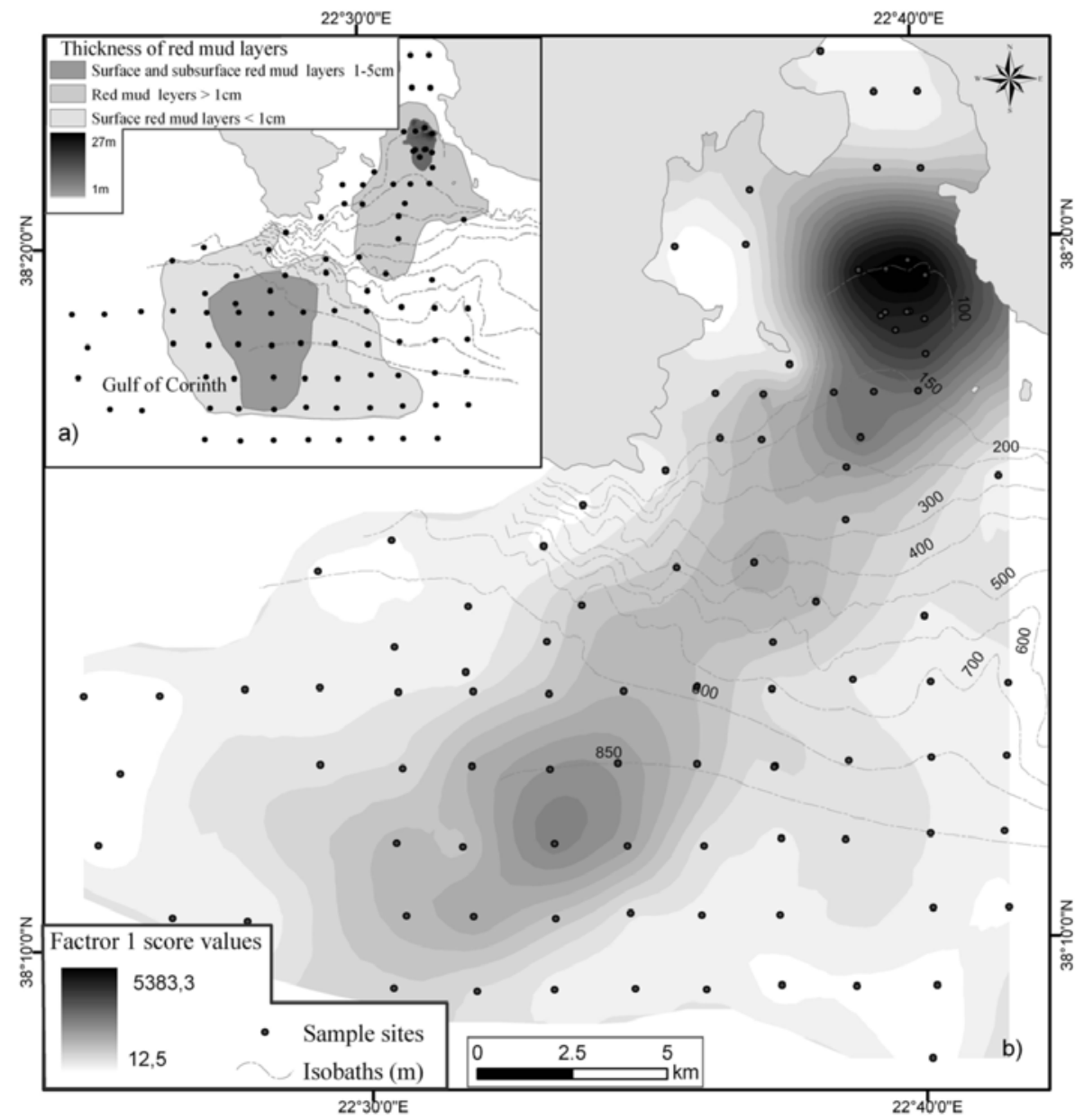

Fig. 4: Spatial distribution of Factor 1 scores of subset 2. Inset shows the surface distribution of red mud deposits on the study area (modified from Iatrou et al, 2007).

Factor 2 explains the significant proportion of $17.5 \%$ of the total variance. Factor 2 show high negative values on $\mathrm{Zn}$ and $\mathrm{Mn}$. The spatial distribution of factor scores shows that high values are on the surface natural sediments on the western part of the Antikyra Bay and on the natural sediments deposited on the east and west extremities of the basin floor (Fig. 5).

Factor 3 explains $9 \%$ of the total variance. Factor 3 exhibits a high positive loading on $\mathrm{CaCO}_{3}$ together with the moderate positive loadings for Si. Spatial distribution of factor scores shows that high values exist on the coastal area of Anikyra Bay $(<100 \mathrm{~m}$ water depth) and on the eastern side of the Corinth Gulf basin. Factor 3 indicates that the natural sediments composition is the result of a coarser carbonate fraction with silicate components.

Factor 4 accounts for the $6,8 \%$ of the total variance and is a single variable factor with a negative pole on organic carbon. Surface distribution of factor scores show that Factor 4 describes the samples that are not associated with red-mud tailings. 


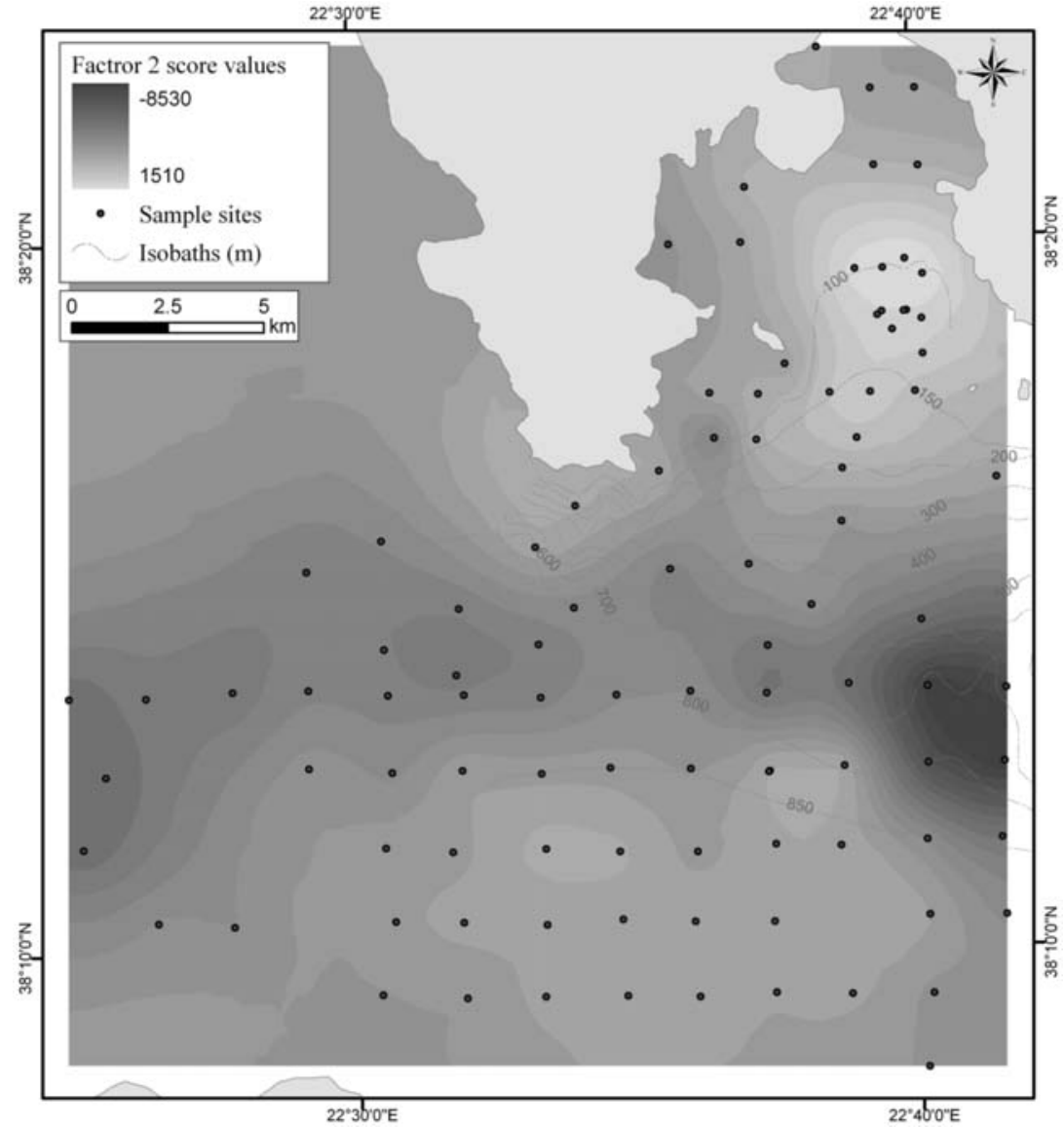

Fig. 5: Spatial distribution of Factor 2 scores of subset 2.

\subsection{Subset 3}

Hierarchical cluster analysis was carried out on the subset 3 which combines geochemical and granulometric data. As Fig. 6 shows two clearly defined clusters are obtained. C1 clusters V, Ag, Ti, Fe, $\mathrm{Pb}, \mathrm{Ni}, \mathrm{Hg}, \mathrm{Cd}, \mathrm{Cr}, \mathrm{Co}, \mathrm{Cu}, \mathrm{Al}$, and silt, clay. These heavy metals are associated with red mud tailings therefore they show strong interrelations. Silt and clay fractions describe the granulometric composition of the red mud tailings. Therefore $\mathrm{C} 1$ expresses the geochemical and grain-size signature of the tailings.

$\mathrm{C} 2$ can be divided into two sub-clusters. $\mathrm{C} 2 \mathrm{a}$ clusters $\mathrm{Si}, \mathrm{Mg}$, with $\mathrm{CaCo}_{3}$ and sand fraction. These cluster elements are not associated to red-mud tailings. Therefore $\mathrm{C} 2 \mathrm{a}$ group may express a natural sedimentation component such as siliclastic and carbonate fraction of sandy components, indicating the complex origin of the natural sediments.

$\mathrm{C} 2 \mathrm{~b}$ clusters $\mathrm{Mn}$ and $\mathrm{Zn}$ with organic carbon. This cluster expresses the background sedimentation components, which are also not related to red-mud tailings. Organic carbon however shows a very weak similarity to the other two cluster elements. $\mathrm{C} 2 \mathrm{a}$ and $\mathrm{C} 2 \mathrm{~b}$ join together at a relatively higher level, possibly implying a common source. 


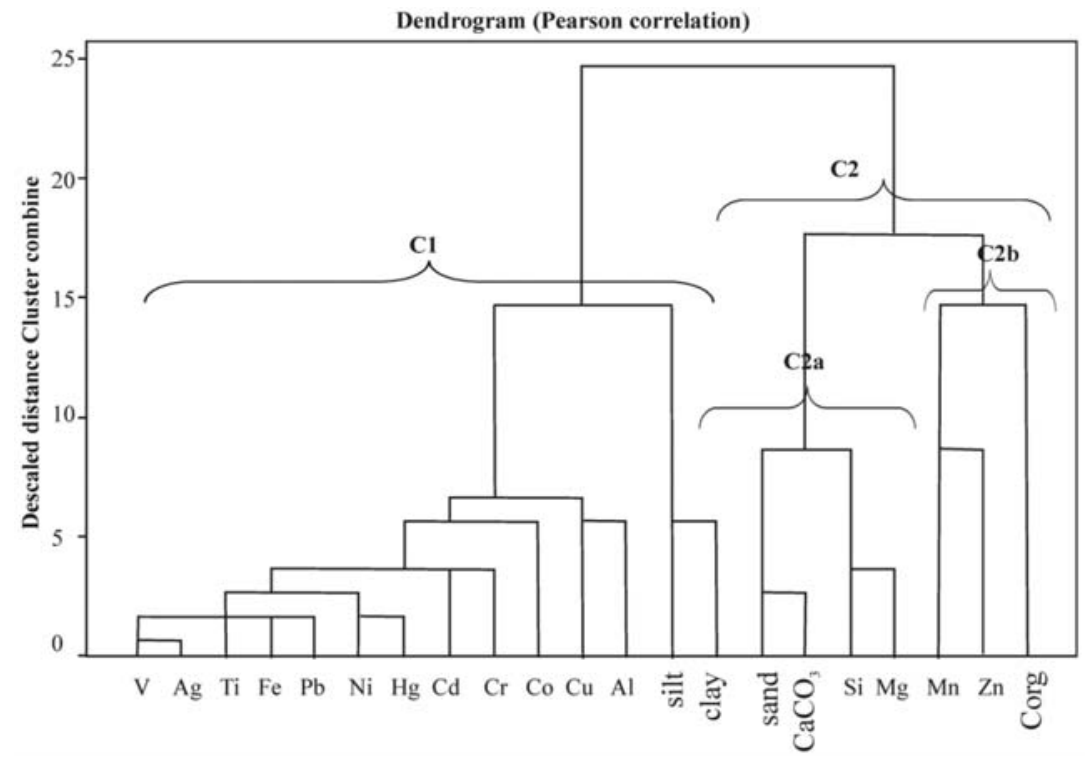

Fig. 6: Dendrogram from cluster analysis of subset 3 between geochemical and granulometry components.

\section{Discussion - Conclusions}

The red-mud tailings are highly enriched in certain heavy metals, such as $\mathrm{Fe}, \mathrm{Ti}, \mathrm{Al}, \mathrm{Pb}, \mathrm{Cu}, \mathrm{Hg}, \mathrm{Co}, \mathrm{Cr}$, $\mathrm{Ni}, \mathrm{Ag}, \mathrm{V}$ and $\mathrm{Cd}$. The disposal of the tailings primarily on the shelf of Antikyra Bay and secondarily, through gravity driven flow processes, on the basin floor of the Corinth gulf (Iatrou et al., 2007) contributes to the abundance of heavy metals concentrations which alter significantly the background levels.

The performance of R-mode factor analysis on the two subsets 1 and 2 dealing with the total geochemical dataset allowed the presentation of specific trends to different dimensions for each subset. Subset 1 provides insight into the temporal distribution of components of the red mud tailings and natural sediments. Subset 2 presents the spatial distribution of those components. The combined analysis of bulk geochemistry and granulometry provided further information regarding the granulometric signature of red mud tailings and the origin of natural sediments.

The effect of the red-mud tailings on the geochemical regime is verified by the fact that the most significant factor describes the red mud components. As it is presented by the distribution of the red mud factor, the score values are higher in the surface sample sites from the Anikyra Bay shelf floor. In addition there is a significant decrease on the score values between the shelf and the basin floor, in all data samples. The above are verified by the geochemical composition of the sub-samples that indicate a decrease on the levels of heavy metals with depth, in the subsurface sediments and shows a significant decrease on heavy metal concentrations between the shelf and the basin. Although the above may be explained by differentiation of the geochemistry of the red mud tailings over the discharge period, mixing processes cannot be excluded. Therefore, red mud tailings could undergo mixing process from the first deposition site on the shelf to the final resting site on the basin floor as it is indicated by the decrease in metal composition along the same direction. The heavy metals that are associated to red mud tailings correlate well with silt and clay fraction of the sediments, indicating the fine sedimentary texture of the tailings.

The factors that express the natural sediments account for less significant proportions because of the strong geochemical masking of the tailings. However, they are able to depict the geochemical sig- 
natures and present indications about their origin.

Factor 2 from the subset 1 analysis coincides with the negative pole of factor 1 from the subset 2 analysis. They express the distribution of $\mathrm{Si}$ and $\mathrm{Mg}$. However $\mathrm{Si}$ is also described by the factor 3 of the subset 2 analysis which is considered to be a carbonate factor. This multiple appearance of $\mathrm{Si}$ may indicate the complex origin of the natural sediments. They consist of silicate fraction and also by carbonate components. Asserting the previous, cluster analysis correlates $\mathrm{Si}, \mathrm{Mg}$ and $\mathrm{CaCo}_{3}$ to sandy fraction indicating that the natural sediments which exist on the coastal area of the Anikyra Bay shelf are characterised by coarser particles.

Factor 3 from the subset 1 coincides with factor 2 from subset 2 . They both account for the distribution of $\mathrm{Zn}$ and $\mathrm{Mn}$. These elements have higher concentration among the natural sediments, particularly in those at the east and west extremities of the basin floor. Thus it is depicted the natural sedimentation which is associated to Mn-hydroxide phase of sediments.

Factor 5 from subset 1 and factor 4 from subset 2 both explain organic carbon content. In cluster analysis organic carbon correlates at a higher level with $\mathrm{Mn}$ and $\mathrm{Zn}$. Thus it may be suggested that Corg cannot be associated to another component. This is also supported by the spatial distribution of Corg on the study area (not given here) which does not exhibit specific trends.

\section{Acknowledgments}

M.I. would like to thank the National Scholarships Foundation (NSF) of Greece for the financial support.

\section{References}

Borrego, J., Morales, J.A., De la Torre, M.L., Grande J.A., 2002. Geochemical characteristics of Heavy metal pollution in surface sediments of the Tinto and Odiel river estuary (southwestern Spain). Environmental Geology 41, 785-796.

Brooks, M., Ferentinos, G., 1984. Tectonics and sedimentation in the Gulf of Corinth and the Zakynthos and Kefallinia channels, western Greece. Tectonophysics 101:25-54

Davis, J.C., 2002. Statistics and data analysis in geology, New York, John Wiley \& Sons, 638pp.

Grey D., Baseden S.,1976. Environmental study of the disposal of red mud waste. Marine pollution Bulletin, 7, 4-7.

Iatrou M., Ferentinos G., Papatheodorou G., Piper D.J.W., and Tripsanas E., 2007. Anthropogenic turbidity current deposits in a seismically active graben, the Gulf of Corinth Greece: a useful tool for studying turbidity current transport processes. In: V. Lykousis, D. Sakellariou, J. Locat (eds.), Submarine Mass movements and their consequences. Springer, pp 149-157.

Papatheodorou, G., Lyberis, E., Ferentinos, G., 1999. Use of Factor Analysis to Study the Distribution of Metalliferous Bauxitic Tailings in the Seabed of the Gulf of Corinth, Greece. Natural Resources Research, 8, 277-286.

Papatheodorou, G., Hotos, G., Geraga, M., Avramidou, D., Vorinakis, T., 2002. Heavy metal concentrations in sediments of Klisova lagoon (SE Mesoloshi-Aitolikon Lagoon complex) W Greece. Fresenius Environmental Bulletin 11,951-956.

Reimann, C., Filzmoser, P., 2000. Normal and lognormal data distribution in geochemistry: death of a myth. Consequences for a statistical treatment of geochemical and environmental data. Environmental Geology 39, 1001-1014.

Sánchez-García, L., De Andrés, J-R., Martín-Rubí, J-A., 2009. Geochemical signature in off-shore sediments from the Gulf of Cádiz inner shelf. Sources and spatial variability of major and trace elements. Journal of Marine Systems, 80, 191-202. 


\title{
SEA SURFACE TOPOGRAPHY IN THE GULF OF PATRAS AND THE SOUTHERN IONIAN SEA USING GPS
}

\author{
Lycourghiotis S. ${ }^{1}$ and Stiros S. ${ }^{2}$ \\ ${ }^{1}$ University of Patras, Department of Civil Engineering, Laboratory of Geodesy, 26500 Patras, Greece, \\ lykourgiotis@upatras.gr \\ ${ }^{2}$ University of Patras, Department of Civil Engineering, Laboratory of Geodesy, 26500 Patras, Greece, \\ Stiros@upatras.gr
}

\begin{abstract}
The topography of the sea, which is changing continuously mostly due to tides, meteorological forcing and climatic changes, is very poorly known in both regional and global scale. In our work we apply a new method, "GPS-on boat", based on differential (DGPS) or kinematic GPS for the recording of the Sea Surface Topography (SST) in the Patras Gulf and the southern Ionian Sea. Analysis of data collected permitted to compile a first map of Sea Surface Topography in the study area. The application of the methodology that we present seems also quite promising for the accurate determination of the Geoid in coastal areas, in which other methodologies provide lower quality results.
\end{abstract}

Key words: GPS, Sea Surface Topography (SST), Geoid, GPS-no boat, Ionian Sea.

\section{Introduction}

Sea Surface Topography (SST) roughly coincides with a surface of constant gravity, the geoid, representing the zero level for height measurement on land. The S.S.T. is usually poorly known, especially in closed gulfs and near-shore areas, which are not properly covered by satellite data merely focusing on oceans. The knowledge of the topography of the sea is important for various reasons, including geophysical (gravimetry-related) studies, meteorological models and climatic change studies. In the past, models of the geoid and the mean sea level for Hellenic area have been presented (Tziavos and Andritsanos, 1999; Andritsanos el al., 2000, Pavlis and Mertikas, 2004).

This paper summarizes results of a first attempt to measure SST along certain traverses in the Ionian Sea and the Patras Gulf using GPS, in particular the method GPS-on-boat. GPS have been widely used for geoid determination on land (Fotopoulos et al., 2000), but the on-boat application are new.The details and results of this technique, which may provide optimum results at coastal areas and semi-closed gulfs, are presented below.

\section{Methodology}

The method of 'GPS-on boat' is based on kinematic GPS (Smith, 1997), the simultaneous tracking of satellites by a moving ("rover") receiver and by one or more stable ("base") receivers on stable ground. The apparent changes of the position of the base receiver permit corrections to the computed coordinates of the rover receiver. This technique requires that both receivers are at relatively short distances, usually up to a few or a few tens of $\mathrm{km}$, so that ambient conditions are quasi-similar, and 


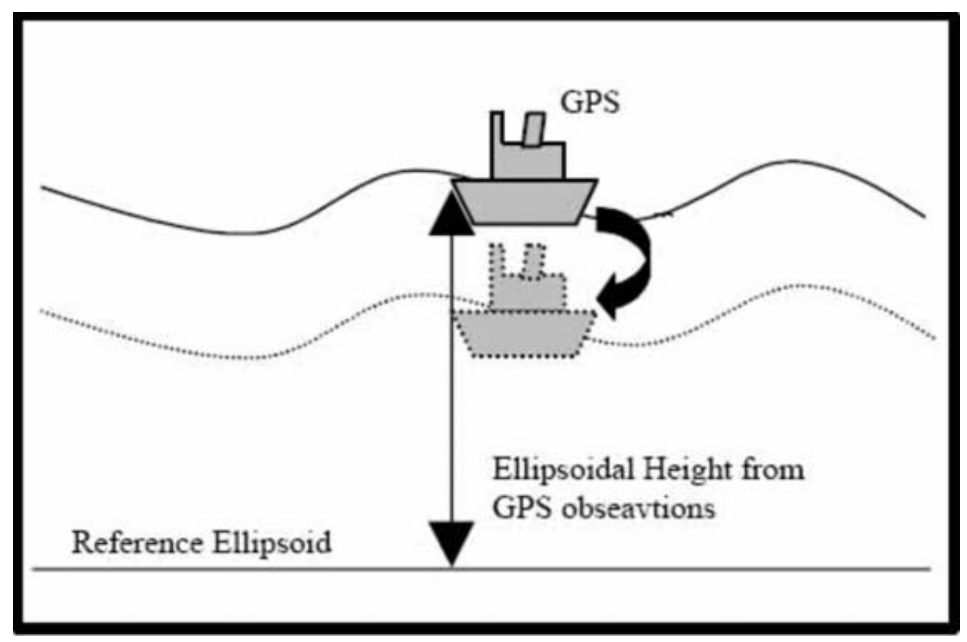

Fig. 1: The "GPS- on boat" methodology. The rover GPS receiver calculates directly the instantaneous elevation of the boat relative to the reference ellipsoid. Filtering of the short-term effects (fluctuations of the sea-level shown as two different levels) permits an accurate elevation of the SST along the boat track.

may permit up to mm level accuracies (Nickitopoulou et al., 2006). In longer distances, this error maybe of the order of tens of $\mathrm{cm}$ (Psimoulis et al, 2007), although there is the possibility of high accuracies at distances $>100 \mathrm{~km}$ (Kashani et al., 2005).

In our study the rover GPS was mounted on a boat which was sailing on the sea-surface, and the computed coordinates were corrected using recordings from base stations on land. Apparently, the elevation of the rover receiver was reflecting the instantaneous position of the rover receiver in reference to the ellipsoid (Fig. 1). This elevation represents the juxtaposition of the SST elevation along the boat track, noise introduced by waves and other meteorological events, elevation differences introduced by tilting of the boat and measurement errors.

However, waves are transient effects usually with a period of a few seconds, the track of sailing boats is relatively smooth but with a zigzag pattern, while the tilt of the boat can be recorded during the sail. Hence, sampling of satellite signals at a rate of 15 second and filtering of the instantaneous coordinates of the rover using statistical approaches permit to minimize all these sources of noise and obtain filtered coordinates, with the vertical coordinate describing the SST with accuracy better than $15 \mathrm{~cm}$.

\section{Data}

The experiment was conducted from 25 June to 3 July 2008. A Topcon HipperPro type GPS receiver was mounted on a 43ft long sailing boat sailing has been used. The sampling rate of the rover and of base receivers was $15 \mathrm{sec}$. In addition, weather data (intensity and wind direction, the atmospheric pressure, temperature and moisture), as well as the slope of the boat were systematically collected throughout the experiment.

\section{Analysis}

Kinematic coordinate recordings from each traverse were analyzed in combination with recordings from the nearest base stations using the PCCDU and Pinnacle software. In certain cases (boat in 


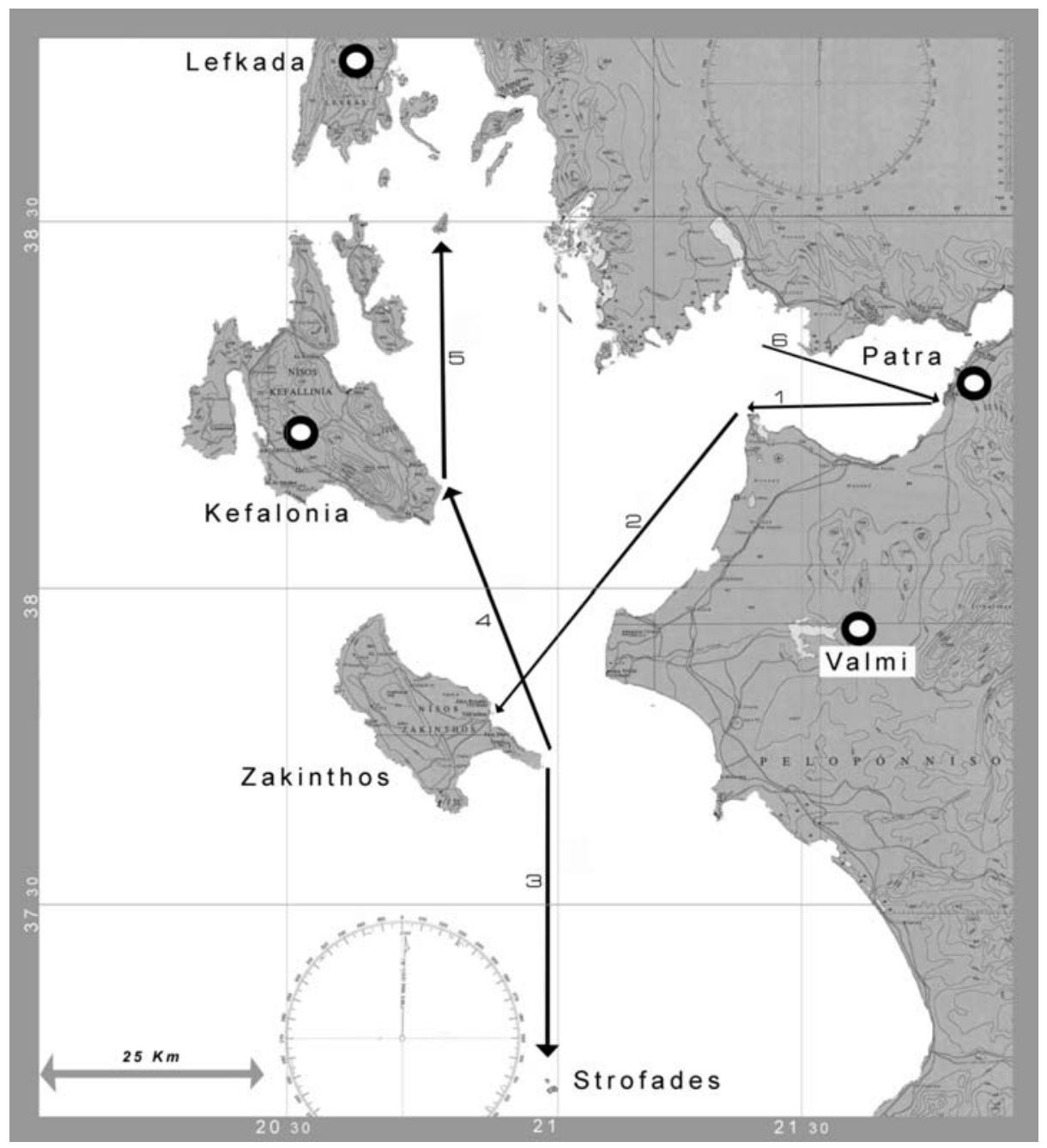

Fig. 2: General map illustrating six (6) different routes of scanning the surface of sea and geodetic GPS base stations. These stations are located at the University of Patras, the Village Valmi, Lefkada and Kefalonia.

harbour) mean values of sea-level elevations were obtained. Finally, the elevation of the rover receiver above the water was subtracted.

Obtained records were characterized by various types of noise, as shown in Fig. 3. This noise was removed adopting the following procedures:

(1) outliers were removed.

(2) systematic offsets with amplitude of tens of $\mathrm{cm}$, sometimes characterizing GPS data for intervals of up to 10min long (see Nickitopoulou et al., 2006), were corrected.

(3) scatter in data revealing random noise was removed using a moving average filter.

In addition, tidal corrections, of small magnitude in the area $(<10 \mathrm{~cm})$ were also made, and mean values of elevation along straight lines (instead of zigzagged lines of the boat track) were computed. 


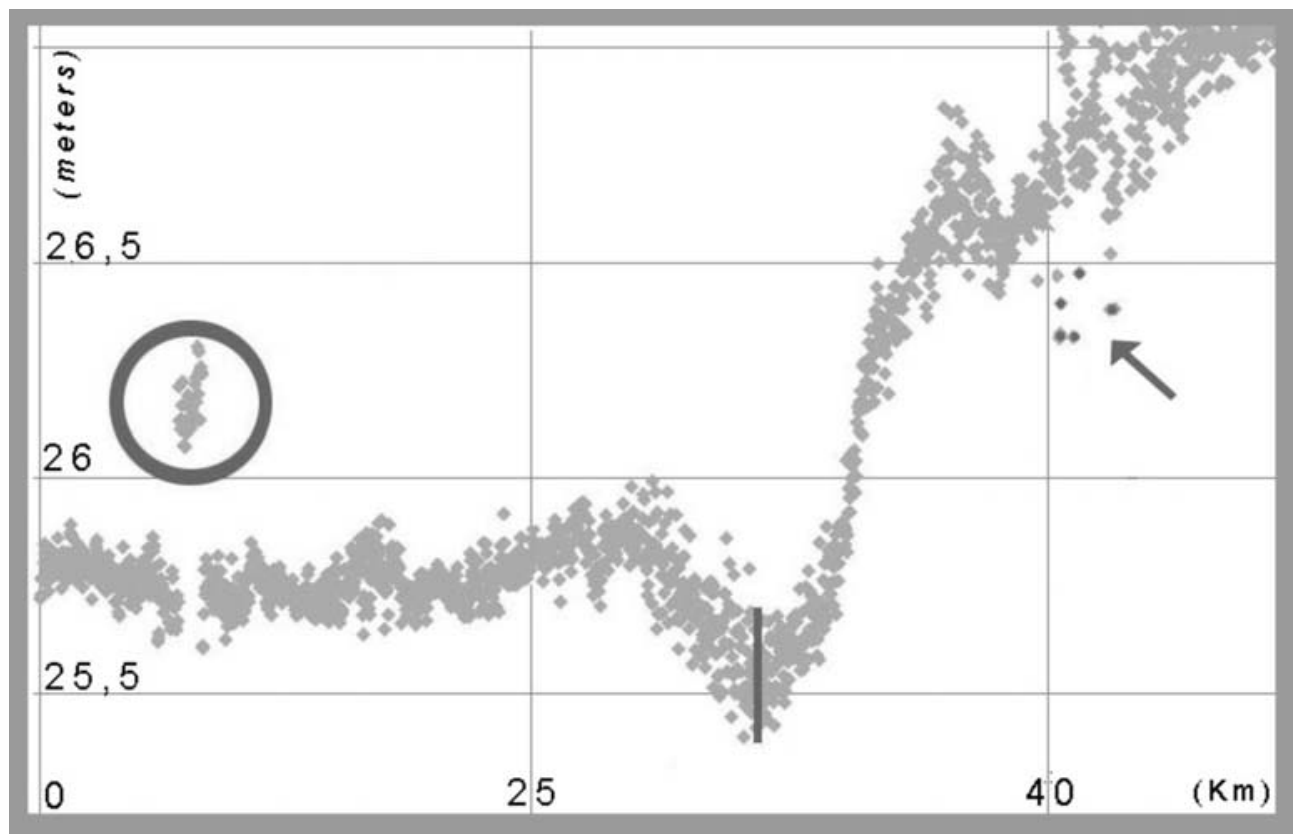

Fig. 3: Recordings of the boat elevation relative to the ellipsoid indicating several types of noise: random (a spread of data), systematic (a systematic offset marked by a circle) and outliers (marked by an arrow). Extract from the June $28^{\text {th }} 2008$ record.

Following this filtering and correction process, a final set of coordinates of the boat position was available. These coordinates indicate the SST elevation along the traverses. The mean sea surface elevation error was smaller than $15 \mathrm{~cm}$. This is due to the imperfections of the atmospheric model as well as to the large distance of GPS base stations from the mobile GPS (Genrich and Bock, 2006) and the multi-reflection of the signal (Leandro, 2009). This analysis is, however, preliminary, and can be repeated using data from additional base stations and different atmospheric models (Kashani et al., 2005) to obtain accuracies one order higher.

\section{Sea Surface Topography Maps}

Figure 4 illustrates the mean elevation of the sea along six traverses. The contours define the Sea Surface Topography around the traverses. These results indicate a smooth drop of the topography and the geoid in the Patras gulf and the southern Ionian Sea. Moreover, these are consistent with the geoid maps of the broader regions derived using other methods (Andritsanos et all, 1995; Cocard et all, 2002).

\section{Discussion}

The technique presented above provide high accuracy results and resolution maps of the geoid and of the Sea Surface Topography, especially in closed waters not covered by satellite data. The accuracy claimed of $15 \mathrm{~cm}$ is an upper level of the method, and it can be reduced using data from other GPS base stations (e.g. Strophades islands) and more refined models. The method proposed is rather expensive because it requires data collected by boats. However, its accuracy can be much higher and using interpolations may provide detailed maps of the SST for different users. 


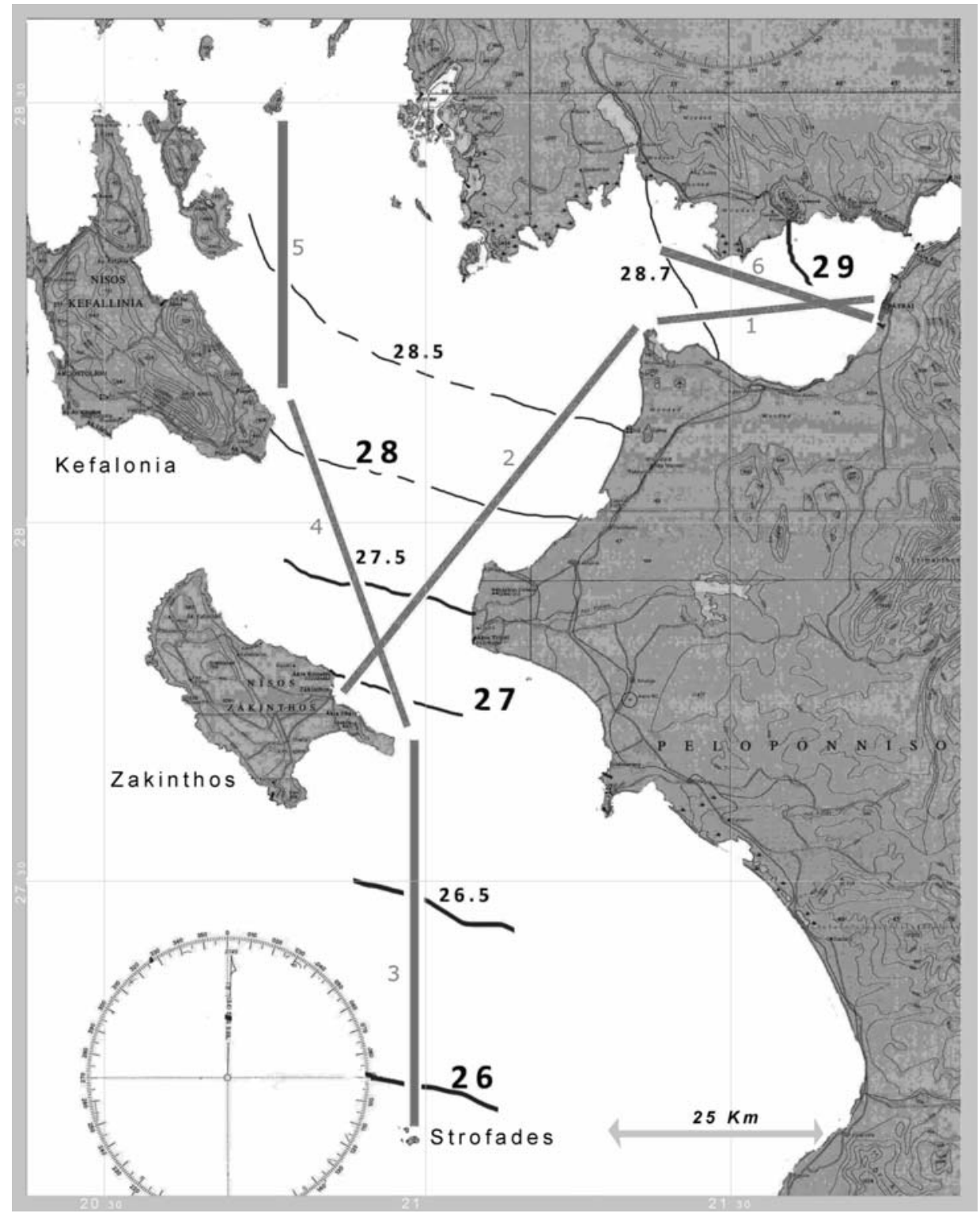

Fig. 4: Sea Surface Topography contours along six traverses.

\section{References}

Andritsanos V., Hryssomalidis H., Kappos G, Kechaidou E, C.K. Pikridas, D.V. Tsoulis, (1995), “Orthometric Height Determination from a Combination of GPS and Gravity Data". Paper submitted to the ION GPS-95 student competition, 1995.

Andritsanos, V.D., Fotiou, A., Paschalaki, E., Pikridas, C., Rossikopoulos, D., Tziavos, I.N., (2000), "Local geoid computation and evaluation". Physics and Chemistry of the Earth, Part A: Solid Earth and Geodesy, 25 (1), pp. 63-69. 
Cocard M., Geiger A., Kahle H.-G., Veis G., (2002) “Airborne laser altimetry in the Ionian Sea, Greece”, Global and Planetary Change 34 (2002) 87-96

Fotopoulos, G., Kotsakis, C., Sideris, M.G., (2000), “A new Canadian geoid model in support of levelling by GPS". Geomatica, 54 (1), pp. 53-62.

Genrich J.F., and Bock Y. (2006), "Instantaneous geodetic positioning with 10-50 Hz GPS measurements: Noise characteristics and implications for monitoring networks", Journal of Geophysical Research, Vol. 111, B03403, doi:10.1029/2005JB003617.

Kashani, I., Grejner-Brzezinska, D., Wielgosz, P. and Wielgosz, P. (2005), Toward instantaneous network-based real-time kinematic GPS over $100 \mathrm{~km}$ distance. Navigation, Journal of the Institute of Navigation, 52 (4), pp. 239-245

Leandro D., (2009) "Investigation GPS positioning «indoor» environment with the help of multipath effect" Boletim de Ciencias Geodesicas, 15, pp. 686-687

Nickitopoulou A., Protopsalti K., Stiros S., (2006) "Monitoring dynamic and quasi-static deformation of large flexible engineering with GPS: Accuracy, limitation and promises", Engineering Geology, 28 (2006) 1471-1482

Pavlis, E.C., Mertikas, S.P., (2004), "The GAVDOS mean sea level and altimeter calibration facility: Results for Jason-1". Marine Geodesy, 27 (3-4), pp. 631-655.

Psimoulis P., Ghilardi M., Fouache E., Stiros S., (2007), "Subsidence and evolution of the Thessaloniki plain, Greece, based on historical leveling and GPS data", Engineering Geology, 90, 55-70

Tziavos, I.N.,Andritsanos, V.D., (1999), "Recent geoid computations for the Hellenic area”. Physics and Chemistry of the Earth, Part A: Solid Earth and Geodesy, 24 (1), pp.91-96. 